\title{
PESQUISA DE STAPHYLOCOCCUS AUREUS EM LEITE A SER PASTEURIZADO *
}

\begin{abstract}
RSPU-B/334
Wilson, D. Pesquisa de Staphylococcus aureus $\epsilon m$ leite a ser pasteurizudo.

Rev. Saúde públ,, S. Paulo, 11:1-11, 1977.

RESUMo: Estuda-se a contaminação por $\mathbf{S}$. aureus do leite a ser pasteurizado, demonstrando que está altamente contaminado. São discutidas us conseqüèncias que a contaminação pode ter e conclui-se serem necessárias medidas urgentes para alterar a estrutura epidemiológica da "linha de leite".
\end{abstract}

UNITERMos: Staphylococcus aureus. Leite, .contaminaçāo. Toxi-infecções alimentares. Enterotoxina estafilocócica.

O "habitat" natural do Staphylococcus aureus é o organismo animal, onde pode ser encontrado na saliva, na mucosa nasal, na pele e no tubo digestivo.

Muitos pesquisadores demonstraram a presença do $S$. aureus na mucosa nasal de pessoas aparentemente normais (portadores). Segundo esses pesquisadores, a proporção de portadores desta bactéria varia entre $30 \%$ e $60 \%$ dos examina$\operatorname{dos}^{4,5,13,15,19}$. Um dos caracteres mais importantes do $S$. aureus, e que motivou a elaboração do presente trabalho, é a capacidade de determinadas cepas produzirem uma enterotoxina termoestável, causadora de gastroenterites.

Já foram descritos alguns surtos de gastroenterite estafilocócica atribuíveis a leite pasteurizado, nos quais houve ou fa-
Iha na temperatura de pasteurização, ou contaminação posterior do leite; pequeno número de surtos, entretanto, pode ser atribuído a leite pasteurizado adequadamente, ou mesmo fervido e não contaminado posteriormente. Em uma série de surtos devidos a leite em pó, há evidências epidemiológicas de que o leite continha enterotoxina estafilocócica antes de ser pulverizado.

Vários surtos foram também causados pela ingestão de queijo. Quando o veículo da toxina foi queijo fresco, pôde-se isolar, do mesmo, números elevados de S. aureus ${ }^{7,10,12}$. Queijos maturados também se constituíram em veículos de vários surtos $3,6,7,8,11,16,17$. Quando se tratou de queijo maturado, entretanto, os estafilococos foram escassos ou não foram isolados, presumivelmente por terem mor-

* Realizado com financiamento da Fundação de Amparo à Pesquisa do Estado de São Paulo. Processo 12 - Médicas 72/243.

* Do Departamento de Nutrição da Faculdade de Saúde Pública da USP - Av. Dr. Arnaldo, 715 - São Paulo. SP - Brasíl. 
WILSON, D. - Pesquisa de Staphylococcus aureus em leite a ser pasteurizado. Rev. Saúle públ., S. Paulo, 11:1-11, 1977.

rido durante o processo de maturação. não antes, porém, de haverem produzido toxina ${ }^{18}$.

A maioria dos dados apresentados refere-se ao Reino Ĺnido ou aos Estados Unidos da América do Norte. Em nosso meio, não temos conhecimento de surtos que tenham sido publicados. Entretanto. os nossos ordenhadores são de baixo nível sócio-econômico e. portanto, têm maus hábitos higiênicos. Dada a ubiqüidade do agente, provarelmente existe uma proporção elevada de portadores nasais entre eles. Pequenas lacerações e abrasões nas mãos são freqüentes e. embora não sépticas, favorecem o crescimento de estafilococos, que são muito mais numerosos em tais lesões do que na pele íntegra.

O leite que chega à usina tem outras possibilidades de estar contaminado com S. aureus:

- devido as mastites estafilocócicas muito frequientes ${ }^{9,14}$;

- a estrutura da "linha de leite" cria condições para a multiplicação do $S$. aureus no leite: a ordenha termina por volta das 6:30 horas e o latão é colocado junto a porteira. à espera do caminhão coletor, exposto ao sol; quando existe um abrigo, este protege o latão apenas do sol a pino, mas os raios obliquos o atingem diretamente; no caminhão, continua sob calor intenso chegando à plataforma de descarga na estação de resfriamento ou usina, entre 11 e 13:30 horas.

De tudo o que se relatou na presente introdução, pode-se concluir que é importante e urgente a realização de uma pesquisa, visando identificar $S$. auteus em leite das nossas bacias leiteiras.

Dessa maneira. como passo inicial. é de suma importância verificar qual a iıcidência de contaminação por $S$. aureus no leite que chega às plataformas de recepção das estações de resfriamento ou das usinas de pasteurização. assim como o grau dessa contaminação devido ao cres- cimento de bactérias, medido pelo número de $S$. aureus por $\mathrm{ml}$ de leite. Estas verificações são o propósito deste trabalho,

MATERIAL E METODOS

\section{Bacia leiteira}

Elegemos para nosso estudo a bacia leiteira de Paraibuna. Esta bacia é explorada por duas companhias, ambas com várias "linhas de leite". Estudamos todas as "linhas de leite" das duas companhias e, portanto, toda a bacia leiteira. que produz cerca de 25.000 litros de leite por dia.

\section{Amostragem}

Colhemos uma alíquota de $10 \mathrm{ml}$ de cada latão, de cada "linha de leite", após homogeneização com agitadores. Os agitadores foram esterilizados entre uma agitação e outra. Para colheita da alíquota de $10 \mathrm{ml}$ utilizamos uma concha, que foi esterilizada entre uma colheita e outra.

\section{Acondicionamento das alíquotas}

As aliquotas foram colocadas em frascos esterilizados. fechados com rolhas de borracha esterilizadas e acondicionadas em geladeiras de isopor, até serem semeadas.

\section{Métodos de laboratório}

\section{1 - Diluição}

Foram feitas, inicialmente, seis diluições em água tamponada: $10^{\circ}, 10^{-1}, 10^{-2}$, $10^{-3} \cdot 10^{- \pm}$e $10^{-5}$. A partir destas diluiçōes foram feitas as contagens em placa, de colônias com caracteres morfológicos de $S$. aureus, usando-se a maior diluição que contivesse de 30 a 300 colônias por placa. O número de colônias foi multiplicado pela recíproca da diluição seguinte correspondente à placa. 
WILSON, D. - Pesquisa de Staphylococcus aureus em leite a ser pasteurizado. Rev. Saude públ., S. Paulo, 11:1-11, 1977.

Posteriormente ficou evidenciado que eram necessárias apenas três diluiçôes: $10^{-3}, 10^{-4}$ e $10^{-5}$. As alíquotas, entretanto, foram guardadas em congelador a $-20^{\circ} \mathrm{C}$ até a leitura das placas semeadas para que, em caso de necessidade, fossem semeadas novamente com outras diluições.

\section{2 - Meios de cultura}

- Meio "Staphylococcus 110" Oxoid. Este meio foi escolhido por ser seletivo e ainda por permitir a verificação de fermentação de manitol (com auxílio de púrpura de bromocresol) e produção de gelatinase (com auxílio de ácido sulfosalicílico).

- Agar nutriente Oxoid - Meio utilizado para incrementação das colônias, para pesquisa de plasmocongulase $e$ DNase.

- Sangue de coelho citratado, para pesquisa da plasmocoagulase.

- Meio Agar DNase Oxoid, para pesquisa de produção de DNase.

De cada placa foram colhidas duas colônias para pesquisa de produção de plasmocoagulase e DNase.

\section{RESULTADOS: APRESENTACAO E DISCUSSAO}

Apresentaremos separadamente os resultados referentes às duas companhias que exploram a bacia leiteira estudada. pois o destino do leite é diferente. Entretanto, na discussão, poderemos nos referir às duas companhias em conjunto.

As Tabelas 1 e 2 apresentam o número de colônias de bactérias com caracteres morfológicos de $S$. aureus por amostra e por "linha de leite".

Gordon Fair *, ao se referir à escolha de água a ser captada para abastecimento público, afirma que se deve buscar a água mais pura possível, pois, é tanio mais fácil tratá-la e torná-la inofensiva a saúde, quanto menos poluída ela for. Em nossa opiniáo, o mesmo se aplica ao leite. Entretanto, de acordo com as Tabelas 1 e 2, o leite desta bacia leiteira, e que será servido à população, está longe de preencher este requisito. Podemos ver que, considerando todas as linhas da Companhia I, 92,9\% das amostras apresentaram crescimento de bactérias cujas colônias apresentavam caracteres morfológicos de $S$. aureus, em uma proporção de 10.000 a 10.000 .000 de bactérias por mililitro de leite; e $37,2 \%$ das amostras, entre 100.000 e 999.999 organismos por mililitro. Vemos as mesmas proporções nas amostras da Companhia II.

Se examinarmos os resultados, linha por linha, veremos que os dados se repetem, com pequenas variações.

As Tabelas 3 e 4 mostram as médias de bactérias por ml, cujas colônias apresentam caracteres morfológicos de $S$. aureus e que apresentaram pelo menos uma colônia plasmocoagulase e/ou DNase positiva.

Podemos ver, por essas tabelas, que a situação é precária e que aquele requisito mencionado quando nos referimos às $\mathrm{Ta}$ belas 1 e 2 está ainda mais longe de ser preenchido.

Como o leite ao chegar à usina é misturado, consideramos válido somarmos todos os resultados e computarmos a média geral de cada uma das companhias. Vemos que a média da Companhia II é algo mais baixa que a da Companhia I. Lembramos neste momento que o leite da Companhia I leva cerca de 45 minutos a mais para chegar à usina do que o leite da Companhia II, o que sugere haver crescimento maior em um leite igualmente contaminado. Tanto no leite da Companhia I, como no da Companhia II, as médias mais elevadas correspondem às li-

* Gordon Fair, Professor de Engenharia Sanitária da Harvard School of Public Health Anotação de aula. 
WILSON, D. - Pesquisa de staphylococcus aureus em leite a ser pasteurizado. Rev. Saúle públ., S. Paulo, 11:1-11, 1977.




WILSON, D. - Pesquisa de Staphylococcus aureus em leite a ser pasteurizado. Rev. Saíde. públ., S. Paulo, 11:1-11, 1977.

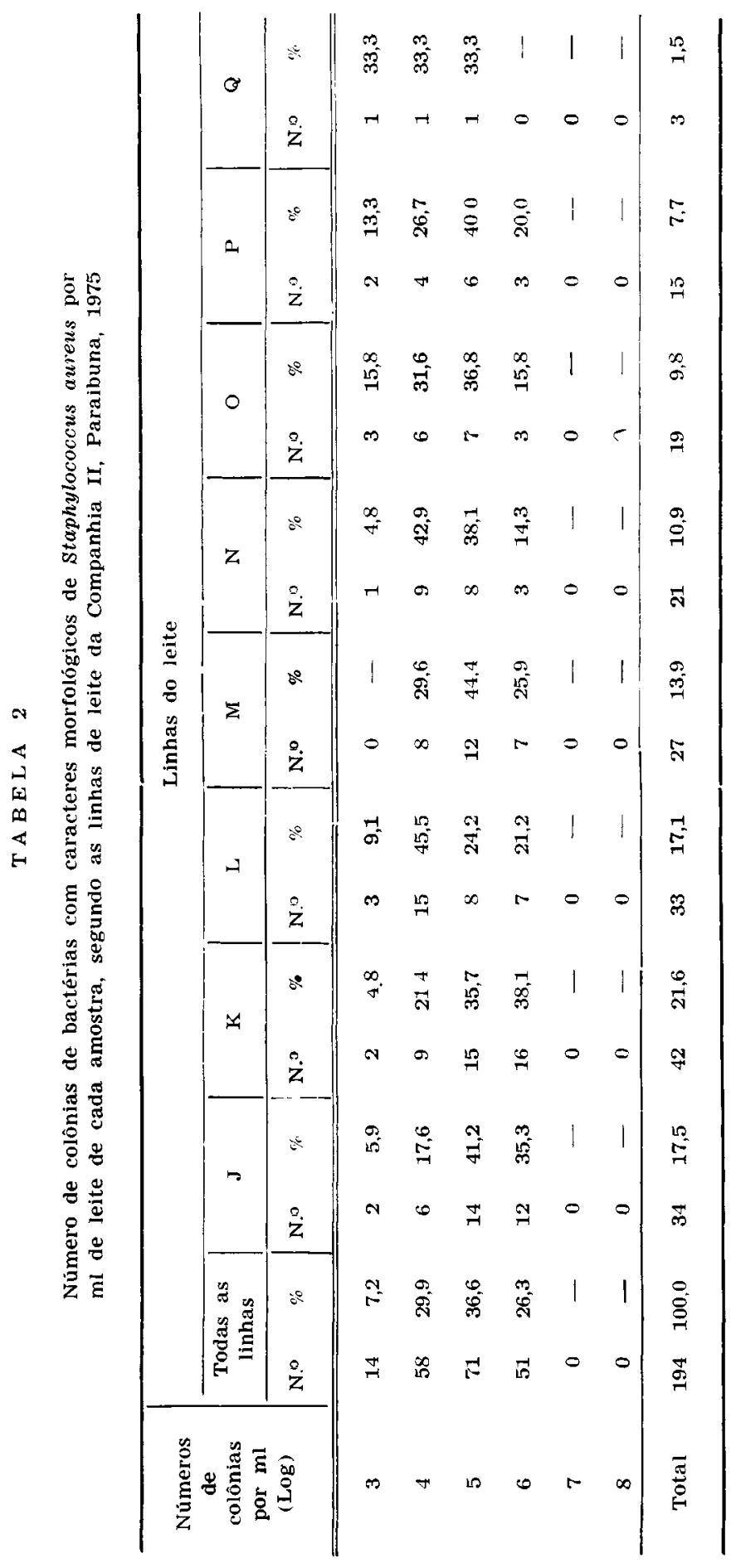


WILSON, D. - Pesquisa de Staphylococcus aureus em leite a ser pasteurizado. Rev. Saúde públ.: S. Paulo, 11:1-11, 1977.

TA B E L A 3

Médias de bactérias cujas colónlas apresentaram caracteres morfológicos de $S$. aurrus e que apresentaram pelo menos uma colônia plasmocoagulase e/ou DNase positiva, por $\mathrm{ml}$ de leite. Companhia I, Paraibuna, 1975

\begin{tabular}{c|c}
\hline Linhas de leite & Nédias de colônias \\
& \\
\hline & \\
A & 4.923 .600 \\
B & 1.788 .300 \\
C & 5.080 .300 \\
D & 205.500 \\
E & 631.100 \\
F & 322.000 \\
G & 1.045 .800 \\
H & 918.100 \\
\hline Todas as linhas & 1.878 .600 \\
\hline
\end{tabular}

TABLA 4

Médias de bactérias cujas colônias apresentaram caracteres morfológicos de $s$. aureus e que apresentaram pelo menos uma colônia plasmocoagulase e/ou DNase positiva por ml de leite. Companhia II, Paraibuna, 1975

\begin{tabular}{c|c}
\hline Linhas de leite & $\begin{array}{c}\text { Média de colônias } \\
\text { por ml }\end{array}$ \\
\hline J & 799.400 \\
K & 1.323 .400 \\
L & 906.500 \\
M & 777.400 \\
N & 196.000 \\
O & 306.900 \\
P & 502.500 \\
Q & 85.700 \\
\hline Todas as linhas & 780.100 \\
\hline
\end{tabular}

nhas que chegam mais tarde à usina, reforçando o que acabamos de mencionar.

$O$ efeito para o consumidor, entretanto. é um pouco menos grave, considerando o leite da Companhia II.

As Tabelas 5 e 6 mostram os caracteres apresentados pelas colônias isoladas. Vemos, através delas. que $88.7 \%$ das amostras provenientes da Companhia I apresentaram-se contaminadas com colônias plasmocoagulase e/ou D Vase positivas e. portanto, patogênicas. assim como $76.4 \%$ das amostras da Companhia II. Estes fatos são deveras alarmantes.

Podemos ver também que 258 amostras da Companhia I e 149 da Companhia II apresentaram $S$. aureus. Se considerarmos que cada amostra corresponde a um latão de 50 litros. teremos que as amostras da Companhia I correspondem a 12.900 litros e as da Companhia II, a 7.450 litros. Vemos, então, que $77.0 \%$ do leite da Companhia I e $76.4 \%$ da Companhia II estão contaminados com $S$. aureus. Como este leite é misturado ao chegar à usina, teremos as seguintes estimativas:

a) o leite da Companhia I apresentou 1.878 .600 colônias de $S$. aureus por $\mathrm{ml}$, em média, nos 12.900 litros contaminados. Este leite foi misturado a 1.650 litros de leite que não se apresentou contaminado por ocasião da colheita do material (mas que em outros dias poderá estar contaminado), resultando em 14.550 litros de leite, contendo $1.671 .306 \mathrm{~S}$. aureus (plasmocoagulase e/ou DNase positivos) por $\mathrm{ml}$ de leite.

b) o leite da Companhia II revelou $780.100 \mathrm{~S}$. aureus por $\mathrm{ml}$, em média, nos 7.450 litros de leite contaminado. Com a mistura deste leite com 2.300 litros não contaminados por ocasião da colheita do material. resultam 9.750 litros de leite contendo $596.076 \mathrm{~S}$. aureus por $\mathrm{ml}$.

O leite de ambas as companhias recebe tratamento semelhante. É colocado em tanque de recepção e, por meio de tubulaçôes, levado a um tanque refrigerado.

Ocorre uma diferença, entretanto, pois o leite da Companhia I é recebido na própria usina, enquanto que o da Companhia II é recebido em uma estação de recepção, onde é refrigerado e transportado posteriormente, em caminhões-tanque isotérmicos à usina de pasteurização. 


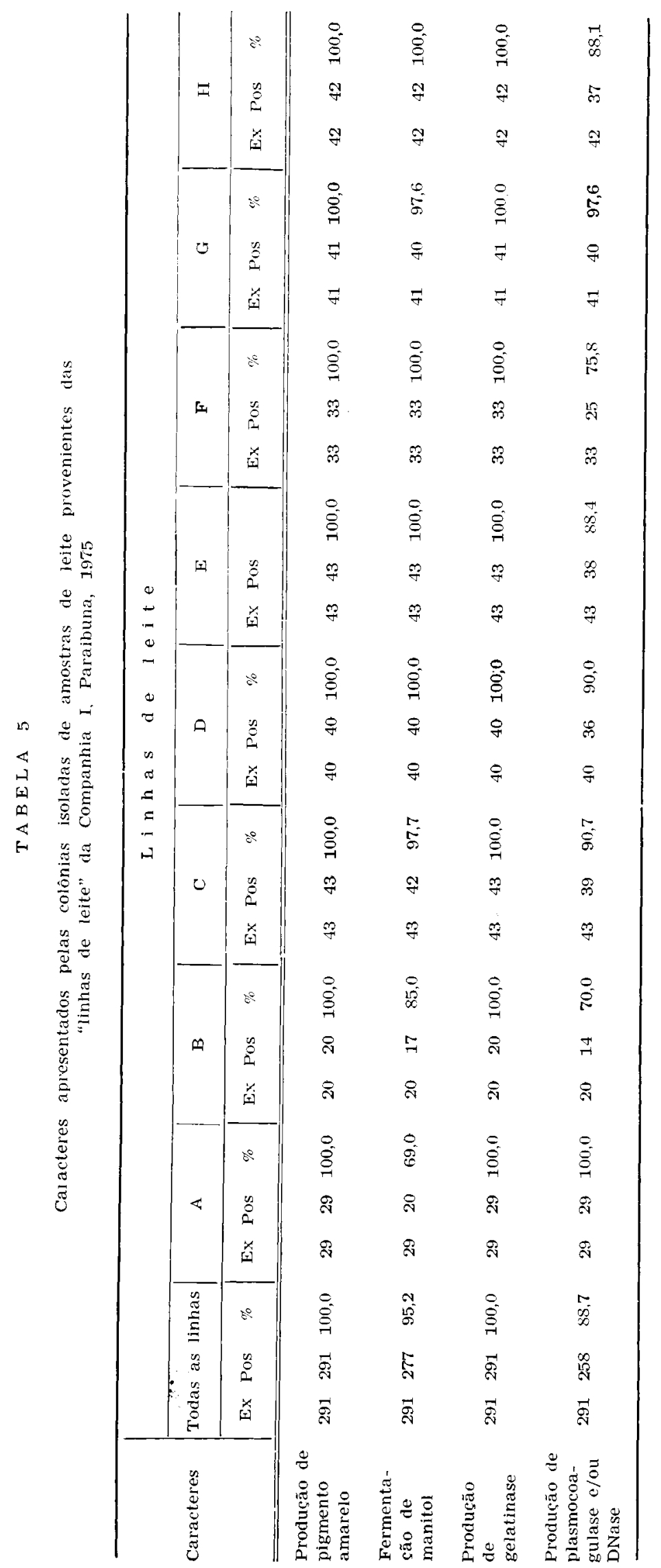




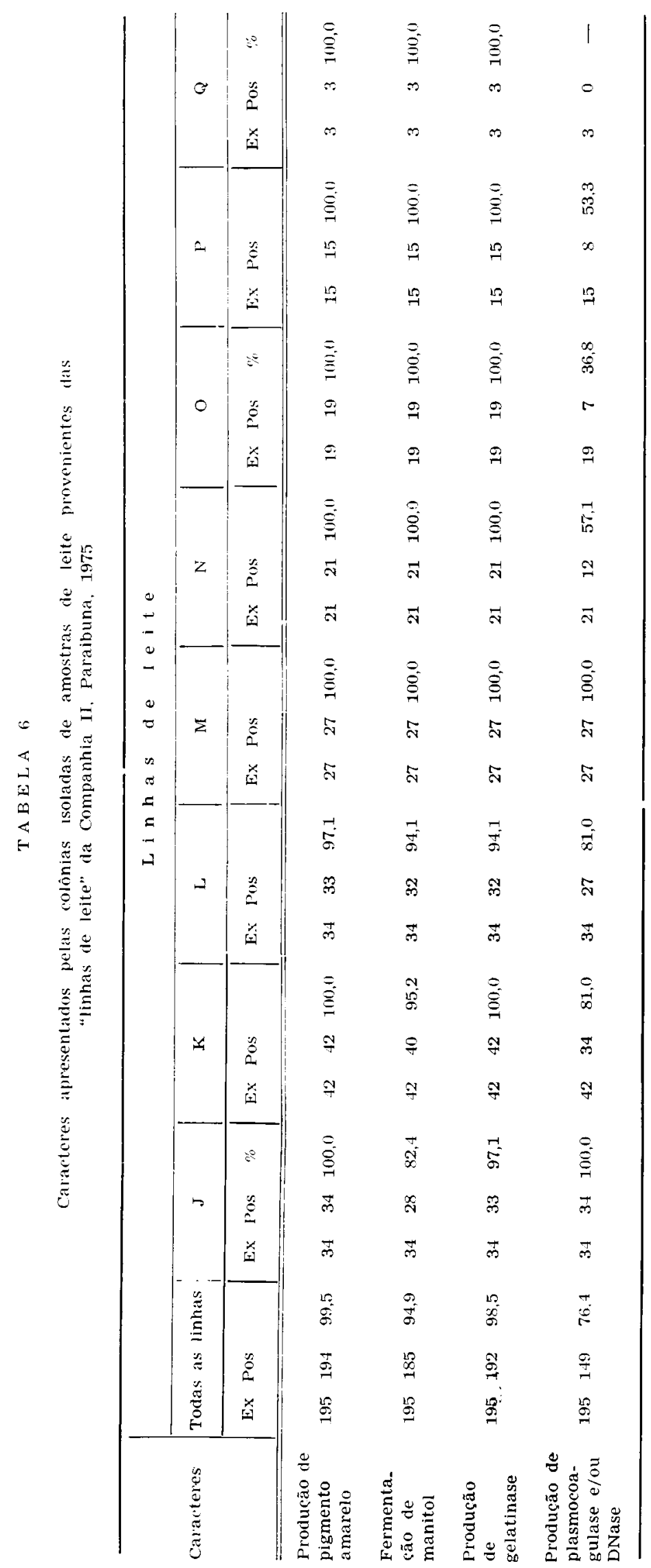


WILSON, D. - Pesquisa de Staphylococcus aureus em leite a ser pasteurizado. Rev. Saúde puibl., S. Paulo, 11:1-11, 1977.

A partir do momento em que é resfriado, cessa o crescimento bacteriano. Sabemos que a produção de enterotoxina depende do crescimento do $S$. aureus produtor desta toxina e podemos concluir que, desde o resfriamento, não mais será produzida, mesmo havendo cepas enterolóxicas no leite. Entretanto, antes de chegar ao tanque de resfriamento o $S$. aureus teve bastante tempo para crescer e a enterotoxina por ventura já formada, não será afetada pela temperatura de pasteurização, por ser termoestável.

O que foi rclatado pode ter três conseqüências:

a) Qualquer falha no sistema de pasteurização acarretará na distribuição de leite contaminado ao consumidor. Havendo também falha no sistema de refrigeração, pré-pasteurização, o problema será agravado. Lembramos ainda que poderá haver deficiência de refrigeração no estabelecimento revendedor, o que oferecerá ao $S$. aureus uma oportunidade adicional para se multiplicar. Poder-se-á argumentar que o leite da bacia leiteira estudada é misturado com leite proveniente de outras bacias e que, assim, haverá diluição do $S$. aureus. Mas, tudo leva a crer que a situação das outras bacias seja a mesma, pairando dúvidas sobre este agente etiológico (ou sua enterotoxina) ser realmente diluído.

Sabemos que as usinas de pasteurização fazem controle bacteriológico em vários pontos do sistema e qualquer faiha será seguramente detectada. Entretanto, dadas as exigências de tempo para identificação de agentes patogênicos, quando a falha for detectada, o leite correspondente ao controle já estará distribuido e, na maior parte, se não todo, consumido. Serão evitados problemas futuros, mas o consumidor sofrerá as conseqüências do atual.

b) Não havendo falha no sistema de pasteurização mas, apenas no de refrigeração, isto poderá permitir o crescimento do agente etiológico e a conseqüente produção de enterotoxina. Esta, sendo ter- moestável, atingirá o consumidor, apesar da pasteurização.

c) A enterototoxina por ventura já formada será, naturalmente, distribuída ao consumidor.

Lembramos aqui o argumento, mencionado anteriormente, que o leite será diluído com aquele proveniente de outras bacias, mas, repetimos, pairam dúvidas, pelo menos a nosso espírito, de que realmente o seja.

Admitindo que haja diluição, persistem duas perguntas: qual o efeito desta diluição sobre o intestino do consumidor? Eliminará a possibilidade de doença, ou apenas amenizará os sintomas?

Referimo-nos aqui apenas ao leite distribuído "in natura". No caso da produção de derivados, o leite permanece tempo mais longo em temperatura ambiente, favorecendo-se, ainda mais, o crescimento do $S$. aureus.

Não pudemos, fazer pesquisa de cepas produtoras de enterotoxina, não podendo concluir seguramente por sua presença; entretanto, não podemos concluir por sua ausência. Lembramos, no entanto, que segundo Chapman e Chapman e Domingo ${ }^{1,2}$, os estafilococos causadores de gastroenterites produzem pigmente amarelo, fermentam manitol, produzem gelatinase $e$ produzem plasmocoagulase. Pelos nossos dados vemos que $84,3 \%$ das amostras da Companhia I e $69,7 \%$ das da Companhia II, apresentaram-se contaminadas com estafilococos positivos para estes quatro caracteres. A situação mostra-se portanto, em nossa opinião, sombria. Vemos, pelos dados apresentados, que a estrutura epidemiológica é bastante favorável ao agente etiológico: o leite é manipulado e o ser humano é o "habitat" normal do Staphylococcus aureus; as características das "linhas de leite" oferecem as condições necessárias de nutrição, umidade, temperatura e tempo, para o crescimento do agente, como ficou claramente demonstrado pelos nossos dados. Podemos acrescentar que a temperatura ambiente - e o leite chega à plataforma de recepção à 
WILsON, D. - Pesquisa de Staphylococcus aureus em leite a ser pasteurizado. Rev. Saúde públ., s. Paulo, 11:1-11, 1977.

temperatura ambiente - variou por ocasião da colheita do material, entre 26 e $30^{\circ} \mathrm{C}$. Sabemos que a temperatura ambiente, na região estudada, pode atingir graus bem mais elevados que estes, o que agravará sobremaneira o problema.

Wilson e Miles" ${ }^{19}$ afirmam que "mais de $50 \%$ das amostras das manadas do Reino Unido contém $S$. aureus, sendo, portanto, surpreendente que surtos veiculados por leite não sejam mais freqüentes". Devemos lembrar que, no Reino Unido, $100 \%$ do leite (ou uma proporção muito próxima) é pasteurizado. Baseados nos nossos dados, podemos afirmar, com segurança, que, se é surpreendente que no Reino Unido não haja maior número de surtos, em nosso meio é mais surpreendente ainda. Por outro lado, entre nós, a informação sobre surtos de toxi-infecções alimentares é parca e não sabemos, realmente, se são ou não frequientes.

Uma explicação plausível é que não haja cepas produtoras de enterotoxina. Admitir que esta explicação seja verdadeira não diminui nossa preocupação, pois, as condições são favoráveis a qualquer tipo de estafilococo e a introdução de cepas enterotóxicas na estrutura epidemiológica atual terá sérias consequiências.

Pelo exposto podemos concluir que são necessárias providências urgentes para alterar a estrutura epidemiológica vigente; estas devem incidir sobre a "linha de leite", no sentido de diminuir ao máximo as condiçóes favoráveis ao crescimento do agente etiológico considerado nesse estudo, como também de outros, que poderão contaminar o leite. Somente assim este precioso alimento não será uma ameaça à saúde.

\section{CON C L U S O E S}

1 - As "linhas de leite", como foi constatado, oferecem condições adequadas de nutrição, umidade, temperatura e tempo, para o crescimento de Staphylococcus aureus, levando a crer que há crescimento da bactéria no trajeto entre o produtor e a usina.

2 - 0 leite apresentou-se fortemente contaminado com Staphylococcus aureus.

3 - Estando o leite contaminado com cepas enterotóxicas, as conseqüências poderão ser desastrosas para o consumidor, por ser a toxina termoestável.

4 - Falhas na pasteurização ou na refrigeração pré-pasteurização, agravarão sobremaneira o problema.

5 - Providências urgentes devem ser tomadas para alterar a estrutura epidemiológica da "linha de leite", no sentido de se desfavorecer o crescimento de bactérias no leite.

\section{A G R A D E I M E N TOS}

A socióloga Maria Kazuko Nakagawa e à farmacêutica-bioquímica Lumi Suguimoto pela valiosa colaboração e também, de especial modo às duas companhias que exploram a bacia leiteira, pois sem sua permissão e cooperação este trabalho não poderia ser realizado.

RSPU-B/334

Wilson, D. [Staphylococcus aureus in milk before pasteurinzing.] Rev. Saúde públ., S. Paulo, 11:1-11, 1977.

ABSTRACTS: The present paper is a study on Staphylococcal contamination of milk before pasteurizing. Gross contamination is shown, and possible consequences are discussed. That measures intended to alter the epidemiologic structure of the so called milk line are necessary and urgent, is the final conclusion of the paper.

UNITERMS: Staphylococcus aureus, Milk contamination. Food poisoning. Staphylococcal enterotoxin. 
WILSON, D. - Pesquisa de Staphylococcus aureus em leite a ser pasteurizado. Rev. Saude públ., s. Paulo, 11:1-11, 1977.

\section{REFERENCIAS BIBLIOGRÁFICAS}

1. CHAPMAN, G. H. - Staphylococcl. Trans. N.Y. Acad. Sci., 9:52.5, 1946

2. CHAPMAN, G.H. \& DOMINGO, E. Applications of new bacteriologic methods to the study and control of Staphylococcus food poisoning outbreaks. J. Bact., 51:405, 1946.

3. FABIAN, F.W. - Cheese and its relation to disease. Amer. J. publ. Hlth, 37: 987-96, 1947.

4. GILLESPIE, E.H. et al. - Pathogenic Staphylococct: their incidence in nose and on skin. Lancet, $2: 870-3,1939$.

5. HALLMAN, F.A. - Pathogenic Staphylococci in the anterior Nares: their incidence and differentiation. Proc Soc. exp. Blol., N.Y., 36:789-94, 1937.

6. HARDMAN, R.P. \& MAC KINNON, N.E. - Food poisoning epidemic probably due to cheese. Canad. publ. Hlth J. , 21:387-93, 1930 .

7. HENDRICKS, S.L. et al. - Staphylococcal food intoxication due to Cheddar cheese. I. Epidemiology. J. Milk Food Technol., 22:313-7, 1959 .

8. HYLKEMA, B. - Poisoning from cheese. Ned. T. Geneesk. 2:1662, 1920.

9. LANGENEGGER, J et al. - Estudo da Incidência da Mastite Bovina na $\mathrm{Ba}$. cia Leiteira do Rio de Janeiro. Pesq. agropec. bras., $5: 437-40,1970$.

10. MANDRY, O.C. - Food poisoning in Puerto Rico. Puerto Rico J. publ. Hith, 9:44-68, 1963.
11. MACAULY, H.M.C. - Cheese poisoning with special reference to the Dover outbreak. Lancet, 2:1012-5, 1922.

12. MacDONALD, A. - Staphylococcal food poisoning by cheese. Mont. Bull. Emerg. Publ. Health Lab. Serv.; 3: 121,1944

13. MacFARLAN, A.M. - Incidence of pathogenic Staphylococci in nose. Brit. med. J., 2:939-41, 1938.

14. ROGICK, F.A. et al. - A mastite subclinica no rebanho produtor de leite tipo "B". Bol. Ind. Animal, 22:91$120,1964$.

15. ROUNTREE P.M \& BARBOUR, R.G.H. - Nasal carrier rates of Staphylococcus pyogenes in hospital nurses. J. Path. Bact, , 63:313_24, 1951.

16. SAVAGE, W.G. - Studies upon toxicity of putrid food. J. Hyg., 20:69, 1921.

17. SAVAGE, W.G. \& WHITE, P.B. Relationship of paratypho:d fever to food poisoning outbreaks. J. $H y g$. $24: 37-44, \quad 1925$

18. WALKER, G.C. et al. - Staphylococo: in colby cheese. J. Dairy Sci., 44: 1272-82, 1961

19. WILSON, G.S. \& MILES, A.A. - Topley and Wilson's principles of bacteriology and immunity. $5^{\text {th }}$ ed London. Edward Arnold, 1966.

Recebido para publicaçao em 21/06/1976 Aprovado para publicação em 10/09/1976 